\title{
Participatory Theatre and Video: Acting Against Violence in Northern Nigeria
}

\author{
Oga Steve Abah, Jenkeri Zakari Okwori and Ogoh Alubo
}

\begin{abstract}
Drama and video are effective tools for stimulating reflection and research on violence. This article describes a research process which tried to understand expressions of identity, constructions of citizenship and prospects for reducing future violence in northern Nigeria, where there have been many outbreaks of violence centred on religion and ethnicity. Researchers and local partners carried out a survey in several communities. They then used the survey findings to develop a drama which was performed in each community and which was followed by a facilitated debate. Participatory video was integrated at all stages. The research findings show that most people do not believe that the contemporary violence is a result of religion. Rather, they see religion as the organising platform. This analysis offers a more nuanced understanding of the conflict than merely labelling it ethno-religious.
\end{abstract}

\section{Introduction}

In this article, we outline how Theatre for Development (TFD) and Participatory Video (PV) have been used as tools to research conflict and violence issues. We argue that the performance art of drama and the visual medium of video are effective tools for stimulating reflection and learning on violence. The research was conducted in Kaduna, Kano and Plateau states in northern Nigeria, where there have been recent and historical outbreaks of violence around issues of ethnicity and religion. As members of the Theatre for Development Centre (TFDC) based at Ahmadu Bello University in Zaria, Kaduna State, we were the principal researchers who led the exercise.

The research set out to explore ways in which citizens can be moved from situations of violence to citizenship through social action - surely a complex and non-linear process, even when it succeeds. Given the context, the Nigerian work focused on the intersection of religion, ethnicity and violence in trying to understand expressions of identity, constructions of citizenship and the prospects for reductions in future violence. Three broad areas of enquiry were religion and inter-faith mediation; Yanbangas (vigilantes), exit communities, violence and citizenship prospects; and tradition, culture, beliefs and violence.

Our interest in researching violence in Nigeria stemmed from the eruption of several violent conflicts in the three states, which became our research sites. Occurring soon after the return to civilian rule in 1999, they centred on ethnic, religious and economic matters. But all were triggered by religious issues.

The overall framework of the research was participatory action research (PAR) which is based on the inclusion of the researched, and sees action, education and consciousness-raising as an integral part of the research exercise. We subscribe to the idea that 'researchers must view the research process as necessarily a coproduction between themselves and the people they are researching' (Burr 1995: 160).

TFD and PV were used alongside other methods in this research process: a quantitative survey (as described in Justino et al., this IDS Bulletin) and semi-structured interviews. This article focuses on TFD and PV, which are ideal methods 
for use in participatory action research. They are useful in information-gathering, providing for a more direct understanding of the experiences of participants and community than that made possible by methods that are principally controlled by the researcher (Rich $e t$ al. 2000). Giving premium to the participation of communities, and offering novel ways of generating and recording data and constructing and contrasting alternative perspectives on reality - both actual and possible - they are also well suited to the promotion of action through self-aware reflection. In this article, we focus on the specificities of using these methods in a context of historic conflict and grievances and recent violent outbreaks.

\section{Context}

With a population of 140 million, Nigeria is the largest country in Africa. It is a mosaic of kingdoms, put together in 1914 by the British colonial authorities for administrative convenience, rather a negotiated union. The colonial policy introduced a system of indirect rule, using traditional rulers to govern the people. The culture, religion and administration of the North, predominantly peopled by Muslims of Hausa/Fulani ethnicity, was left mainly intact. For the minority ethnic groups of the North, this meant that their rulers were descendants of those who had led a nineteenth century jihad (holy war) against their communities, imposing Islam and raiding for slaves. A sedimented anger thus existed among the minorities after Independence in 1960.

The mosaic structure has continued to define the nature of the state and the relationships between its component units. Nigerians see themselves as belonging to their ethnic groups before they see themselves as Nigerians. The concept of citizenship has not been translated for every Nigerian to know what it means, so is not widely understood; and instead, ethnicity and religion define senses of belonging. Most people do not see violence as a legitimate means of claiming citizenship, as our research confirms, yet they agree that when their ethnic or religious identities are threatened, they can defend it by means of violence. There are therefore unresolved questions over the legitimacy and justification of violence as a means of claiming citizenship.
Since Independence, Nigeria has been beset with various forms of deeply-rooted conflicts - ethnoreligious, indigene-settler syndrome, and disputes over resources such as land and oil either as a way of expressing discontent, or a means of agitation for recognition or resource control. The indigene-settler question in Nigeria concerns the difference between autochthons and others who have migrated to settle in places other than their ancestral homes. This difference is perpetual because no matter how long one has lived in a place, one remains a settler and cannot be recognised as indigenous to the place.

Whereas citizenship is a constitutional matter, indigeneity is ancestral.

Of three states involved in this research, Kano is predominantly Hausa/Fulani, whereas Kaduna and Plateau are ethnically mixed. Half of the population of Kaduna is Hausa/Fulani but the southern part of the state comprises several largely Christian ethnic groups. Plateau is home to numerous mostly Christian ethnic groups, with only 25 per cent Hausa/Fulani. Although the government has explained violent conflicts in the three states as land disputes, in reality the ethnoreligious and the indigene-settler syndromes have dominated the eruptions of violence.

Kaduna experienced 24 Muslim-Christian conflicts between 1977 and 2002. ${ }^{1}$ The conflicts of 2000 were particularly bitter, resulting from an attempt to introduce Sharia law as a governing principle in the state. Violence erupted when Christians began protesting the findings of a committee set up to deliberate on introducing Sharia, which reported that only a tiny minority of representations had opposed Sharia. Muslim youths retaliated and with an army of thousands of Almajiris (Qur'anic pupils), they set about burning, killing and looting. The Christians retreated, regrouped and launched their own retaliation, and the violence spiralled.

Kano had 13 conflicts between 1980 and 2004 . Historically, conflict in Kano is marked by reprisal killings, beginning in 1967 when Igbos were killed in their thousands as a result of the death of the Premier of Northern Nigeria during a coup led by Igbo officers. A reprisal killing in September 2001 resulted from rumours of killings of Muslims in Jos, which prompted 200 Muslim fundamentalists to disperse throughout the city to eliminate Christians. Soon after, a 
peaceful demonstration against the US invasion of Afghanistan became violent when fundamentalists just coming out of the mosque began to attack Christian businesses and churches.

Plateau had 25 conflicts between 1980 and 2004. Two conflicts in 2001 stand out: a Christian woman who was said to have refused to turn back at a Muslim road barricade during their prayers was beaten up as a result, sparking a mobilisation in her support and revenge. Soon after, when a Muslim was appointed to a significant State post, indigenes under the umbrella of the Plateau Youth Council condemned the appointment because he was a settler, and promised mayhem if the appointment was not rescinded. His Muslim relatives rallied round him leading to a violent conflict.

The three states thus present ample examples where Islam and Christianity, intersecting with ethnic identities, were the basis for staging various conflicts which had deep roots in the design and construction of Nigeria. A new settlement pattern has emerged in Kaduna, Kano and Plateau as a result of the spate of violent eruptions. Some people have moved to enclaves where they feel safer. These are wellknown as Muslim or Christian areas and each side is afraid of venturing into the 'enemy' territory. In this difficult research terrain, our choice of methodology was influenced by the need to make the research not only possible but useful.

\section{The research process}

We decided to use a participatory approach employing TFD and PV because:

- High levels of illiteracy in the communities called for tools that people could fully understand, and through which they could articulate their views in their chosen language and manner.

- They attract participants. Wonderment about video makes people eager to speak to the camera. PV creates trust: the speaker's views cannot be modified by others.

- PV and TFD, used within a PAR approach, afford significant participant ownership of the research tools and process. The supplier of the information is covered by 'artistic licence', which ensures their material is treated as fiction, removing fears of repercussion. Also, since in PV what people say is verifiable and traceable to them, they are most likely to 'tell it as it is' or as they know it to be.

- Participatory process, including the open presentation of 'findings' or outcomes to the dramas and invitation to intervene in them, is a spur to reflection and self-critical analysis.

- Open presentation of the dramas is a platform for surfacing a plurality of views on emotive issues in a peaceful and constructive way. Allowing participants and the public to change the ending of the drama sows a seed for the communities to change their violent reality next time they are threatened with an outbreak of violence.

In each state, the research took place in two Christian safe-havens, two Muslim safe-havens, and one community with mixed settlement. Working within a position canvassed by Burr (1995: 160) that 'researchers should acknowledge their own intrinsic involvement in the research process and the part this plays in the results that are produced', we addressed the implications of our own Christian identity by devolving the research itself to local people in each community. It was these local researchers who actually went round their communities performing and applying the questionnaire survey and the PV. The second factor we used to diminish tensions around our identities and origins was to play up the fact that the research was being done by a centre in Ahmadu Bello University (ABU). ABU has so much respect that following the mention of the name, closed doors open: people believe that an ABU centre cannot be behind something that will harm them.

TFDC engaged two liaison people, one man and one woman, in each community, who belonged to community-based organisations (CBOs) there, and were well known and respected both among their communities and by the TFDC principal researchers. These people were intermediaries between the communities, the chiefs and TFDC. Each community also selected a man and a woman to be part of the research teams. Team members were trained to be community researchers, gathering information, performing the drama and using PV. They remain a resource group in their communities, to give reality to the project and to ensure that the discussions are sustained. 
First a quantitative survey was carried out, with 145 respondents, gathering data on community relationships and unsafe places, frequency and severity of episodes of violence, and a range of demographic, economic and livelihood variables. The research team then interviewed ten individuals in each community: the Chief, a religious leader, two adult men, two adult women, two younger men and two younger women. In these video-recorded interviews, information was gathered using a checklist based around the three principal components of the research.

The resulting information was used by the whole team in each state to develop a drama, which was performed jointly by the teams from all five communities. The proposal to the community was to develop a drama piece in which the central character encounters friends, colleagues and neighbours who have different opinions on religious and ethnic issues from him.

The members of the CBOs devised the dramas and performed them. The building of the drama in each of the States allowed the young people to engage in a discussion of the issues, to learn the drama process and how to facilitate discussions and questions at the end of the performance, around who had gained and who had lost from the riots.

During the process, from community research through drama-making, to the discussions at the end of the performances, PV was used to record interviews, capture the pains and frustrations on people's faces, and record the debates and plans at the end of the performances. It also recorded messages from people on opposite sides of the religious and ethnic divides, asking for recognition of a common need for basic survival among the poor; for the poor Muslims and Christians to recognise that it is the politicians and elite workers who benefit from their suffering. Such recognition and understanding underscored the need for peaceful coexistence. The recordings were done by the community researchers, who had been trained in basic camera technique.

In every location, there was a lively postperformance debate. Performers became facilitators, asking their community members for comments on the issues they saw in the drama. When disagreements arose, members of the audience were invited to assume the role of the character in the contested section of the drama, allowing for debate and further analysis of the issues. Theatre thus played multiple roles of information-gathering, feedback, analysis and triangulation or validation of facts, while PV played a role in building up a broadly accepted and pluralistically-constructed version of events, and in data-recording on both content and process.

\section{Findings}

Rehearsals and performances were a learning experience for participants. Working together, Muslims and Christians were enabled to hear different and unimagined sides of the story, and in ways they never had before. For example, the Muslims discovered that the Christians, like them, were victims of rumour, and that Christians were equally victims of the greed of politicians. Spontaneous outbursts such as, 'You see, we have all been used and dumped', and 'We have killed each other for nothing', were common.

Each drama represented happenings after violence had already occurred; none depicted the violence itself. In Kaduna, the drama was about a young carpenter Musa sitting desolate and despondent in his workshop. His clients have been reduced to a trickle because most have relocated to communities where they feel safe and are scared of visiting their old communities. We see him warn his friend who has fallen in love with a girl from 'enemy territory' not to visit the girl as he would doubtless be killed. The friend visits all the same and instead of being killed is well received. He also brings back the news that government has convened victims of the violence to a school that day, to make compensation payments. Musa and others rush and benefit from the exercise. Victims get paid only onethird of the compensation due to them. While the core messages of rumours and deception of the poor by the elite remained in all three states, in Kano the central character became a trader; in Plateau, a community worker.

The drama indirectly identified actors in the violent events. Speech patterns and mannerisms of walking and behaviour easily gave away the real people involved to be mostly Almajiris in the case of the Muslim perpetrators and community youths in the case of the Christian perpetrators. Almajiris are young boys, disconnected from their 
parents and attached to Islamic Mallams (teachers) who tutor them in Qur'anic education. Often begging for food, their vulnerability makes them fertile ground to be recruited and used as foot soldiers in times of violence. The youths in the Christian communities are mostly secondary school drop-outs who do not have jobs or means of survival and who have taken to drugs and drink for solace. They see violence as an opportunity to vent their anger on those who they believe are responsible for their state of existence. The media and most of the literature on violence points to Islamic and Christian fundamentalists as the perpetrators of violence, but the dramas suggest something different. This information would not have surfaced had we just conducted a questionnaire survey.

The research findings show that in terms of how organised religion impacts on violence, deeply rooted animosities lie behind the eruptions. The quantitative survey showed that most do not believe that the contemporary violence is a result of religion. Rather, they see religion as the organising platform. This analysis offers a more nuanced understanding of the conflict than merely labelling it ethno-religious.

Prior to our fieldwork, our understanding of the crises did not include rumour as a major vehicle that propelled the crisis, and indeed the word 'news' was constantly used rather than 'rumour'. However, it came out clearly from the drama that rumour was a decisive factor in the escalation, and in some instances the instigation, of violence.

Most of our data suggests an acceptance that no one, including government, has legitimacy or authority to commit violence, yet an agreement that when one's sense of belonging is threatened, one will react violently. In fact as one youth in Kaduna put it: 'Violence is the only language that makes the authority (governments) to listen [sic]'.

Views emerging from the research call into question the efficacy of interfaith dialogue as a dispute resolution strategy, by dislodging the idea that religion was the cause of the violence. We found that most respondents were unaware of most interfaith dialogues, even the highprofile initiatives by the Kaduna State government involving international inputs. Many respondents in Kaduna believe that the relative peace there now is due to the government correcting some injustices by giving chiefdoms to many aggrieved southern Kaduna communities, and throwing some development work in their direction.

In the final analysis, it emerged from our research that Muslims and Christians equally experience neglect by government. This was useful in tackling misconceptions by both groups that their 'rivals' were better off than they were.

\section{Reflections and insights on approach and methods}

In broad terms, the TFD and PV, the quantitative research and qualitative interviews complemented each other very nicely throughout. The quantitative component provided useful information on the areas most affected by the violent incidents in Kaduna, Plateau and Kano States. The findings debunked the perceptions of both Christians and Muslims that the other had more privileges and access to social amenities. The survey revealed that ordinary citizens in all 15 locations surveyed were, irrespective of religion, relatively poor. Drama articulated people's perceptions and understanding in concrete images. PV recorded the performances - complete with gestures, expressions and emotions - and captured the messages from different communities and groups.

The relationship of TFD to PV in this research exercise is that the one provided information for the other. We watched the recorded narratives of interviewees recounting their experiences of violence. These narratives were reconstructed into drama for performance, changing accounts on film into physical theatre in front of community members. What looked distant in the video became immediate and tactile in the dust of the community space. At the same time however, the performed piece returned to the virtual community space in the video after it was recorded. The function of this is that the drama pieces become transportable materials to be shared in other communities. They also enter the offices of policymakers who view them from the comfort of their executive chairs. While the drama used the information recorded from the interviews to build its narrative and dramatic sequence of events, the video recorded the text of the drama and widened the audience. 
By allowing people to argue their cases in public, TFD and PV promote identification with and ownership of the research process. PV enables the people to speak directly as they wish to the camera buoyed by the sense of self-worth and power that comes with the camera being on them and the microphone in their hand. TFD allows participants to express themselves in the context of drama protected by the sense that the drama process, being fiction, brings no liability for their actions and utterances since they are not themselves but pretending to be others.

Many of the attributes we describe here reinforce the suitability of TFD and PV as tools for the participatory research genre. Drama and PV processes enable 'the actors [to] interpret events and actions not so much by imposing on them a fixed structure as by "translating" the events and actions over time and by developing new frameworks and "stories" for their (re)interpretation' (Lanzara cited in Colombo 2003: 5). The appeal and relevance of such reinterpretation and reflexivity are underscored by the fact that the work we do is mostly situated in oral cultures where the ability to read and write are limited or non-existent. Instead of being constrained by specific questions, people were enabled to connect with the incidents of violence in a reflective manner, through testimony or narration of their experiences during the drama and during the PV discussion. This outpouring appeared to allow them purgation and relief.

In drama and PV, accounts are rendered in action and signs which present multiple facets of an issue, allowing the audience of participants to draw their inferences and conclusions. This has important implications on an analytic level: instead of trying to explain the nature of an account in relation to an external reality predefined by the researcher, the account emerges as alternative versions supplied by the participants (Colombo 2003). The 'interpretative repertoire' (Potter and Wetherall 1987) made available through TFD and PV is a reservoir of available cultural and historical linguistic and paralinguistic devices which people continuously draw upon to construct and reconstruct accounts. In these respects, the narration that emerged was not so much a reconstruction of events as an analysis of the motives behind the actions or behaviour of performers and community participants (Sarbin 1986).
A further useful characteristic of TFD and PV in this research context is that they were useful devices for distancing and depersonalisation. Both techniques facilitated the discussion of sensitive matters which respondents would not talk about in interviews or answer in questionnaires: in all three states some questionnaire respondents refused to answer questions about who had been involved in the violence. Some characters in the dramas were played by the people that experienced the incidents in real life, who, while not prepared to admit their involvement in reality, accepted performing it in the fiction of the play. In one location a female actor showed in her role an intricate knowledge of how a particular house was torched, that only a participant in the act could have known.

We observed too that even when people declined to name perpetrators of violence, body language sometimes conveyed the information nonverbally: a young man turned nervously several times in the direction of another young man when the question of perpetrators came up. ${ }^{2}$ Drama and PV give us the full range of signs, movements, posture and expressions which are used to convey or hide meanings. On this scope for eliciting non-verbal communication, we argue that drama and PV provide a version of Geertz's (1973) 'thick description'. Geertz argues that interpreting signs or body language as well as verbal language gives access to the full range of meanings, real or potential, thereby providing a thick description which turns out to give richer and better information than would otherwise be given. In real life, most meanings are constructed not just by words, but by signs and body language. Eliciting these through TFD and then capturing them for posterity using PV generates a permanent and rich source of complex data including body language, facial expressions, postures, movements, bodily adornment and material culture (Heath and Hindmarsh 2002; Bottorff 1994; Hodder 2000).

The combination of TFD with PV proved useful in 'fixing', on film, the ephemeral and the untransportable that arose in the dramas. While TFD can only be experienced at the place and the moment when it is happening, the videos enabled community members to see what happened in other communities, hear the views of others and see the multiple ways these were 
articulated, including their emotions and bodily expressions. No dramatic action can be repeated exactly twice, but PV can record the action and repeat it several times over, which allows for deeper reflection.

\section{Contribution to reducing violence?}

We conclude by weighing up the contribution of our research to knowledge and to opening up possibilities of action for change. Our research has, in our view, produced good results and useful knowledge. We understand better the interconnected factors that lie behind violent eruptions in Kaduna, Kano and Plateau states. Control of political power, economic control, poor social provisioning, religion, ethnicity, and the correlations between all of these, serve as both latent reasons as well as triggers for such eruptions. The development of an agenda for social change needs to be informed by such a nuanced understanding of these issues and the ways in which they play out in the lives of the ordinary people, the victims of the crises. While we cannot claim that our research has itself brought about any significant social change within this period, we do conclude that it has raised people's consciousness in a number of ways that can prepare the community-based organisations to embrace social action and the change that it produces.

The stories of Musa and Jafaru from Kaduna, and Hajiya in Jos Plateau State are emblematic of the project's consciousness raising achievement. Prior to the research process in August 2007, Musa would not leave his Muslim enclave in the northern area of the Kaduna metropolis to go to the south of Kaduna: 'Since the violent incidents in Kaduna which led to Christians and Muslims living in different parts of the city, I have not gone south of Kaduna. If I go [...] I will be killed!'. But in the course of the research, he travelled to Kaduna south and he was not killed. Instead, he was reunited with friends that he had not seen for five years. Musa also joined others to perform inside the church, which he had perceived as the place of worship as well as a symbol of those who would kill him. Instead of being killed, he took part in a discussion on community building and peaceful coexistence. Jafaru, who ordinarily would not interact with Christian youth, requested after the research to join their Association in Kabala
West, a Christian community. After watching the drama performance in Ungwan Rogo, a Muslim community in Jos, Hajiya, a septuagenarian woman, advises that Jos must return to its former self of integrated living if life is to be meaningful and if there is to be progress.

Two factors led to these outcomes. One is the participatory method used; the second is the experiential lives of the communities. This is the most important meaning of 'creating ownership' in this research case: not just participants' ownership of the research process but participants' ownership of arguments and issues that shape their lives. Owning the research process through participating in drama, discussion and video-making sharpens the debate and understanding of those same issues. But the creative methodology afforded the additional opportunity to come to own their perceptions, attitudes and mindsets, through interrogating their 'common sense', 'news' and stereotypes of 'the other'. The fact that people were talking about their real life experiences of violence lent an urgency to the subject matter; and when this urgency encountered an enabling method, people engaged constructively.

From data collection, through analysis and story formulation to presentation and postperformance discussion, our drama and PV methods were engaged in action as well as research. This is because they acted within and upon existing situations in ways that could produce change. By participating, the communities increased or validated the knowledge at their disposal. In the light of new understandings gained by experiencing other perspectives and watching the videos and the dramas as active spectators, they unpacked the existing situation and were presented with choices for altering it in a transformative way. By so doing they made an 'an imaginative leap from a world of "as it is" to a glimpse of a world "as it could be" (Wadsworth 1998: 8). What remains to be seen is whether, in future, these participants engage so readily and so literally in circulating rumours that might lead to physical harm, or respond readily to inflammatory calls to violence from political elites. They have glimpsed and enacted their world 'as it could be', and consigned it to film; and they seemed to prefer it. 


\section{Notes}

1 This figure and those in subsequent paragraphs come from our own monitoring of violent incidents in the three states; we are aware of them because we live near them and indeed were affected by them.

\section{References}

Bottorff, J.L. (1994) 'Using Videotaped Recordings in Qualitative Research', in J.M. Morse (ed.), Critical Issues in Qualitative Research Methods, Thousand Oaks, California: Sage

Burr, V. (1995) An Introduction to Social Reconstructionism, London: Routledge

Colombo, M. (2003) 'Reflexivity and Narratives in Action Research: A Discursive Approach', Forum: Qualitative Social Research 4.2: Forum Qualitative Sozialforschung/Forum: Qualitative Social Research 4.2 [online Journal], www.qualitative-research.net/fqs-texte/2-03/ 2-03colombo-e.htm (accessed 3 March 2007)

Geertz, C. (1973) The Interpretation of Cultures, New York: Basic Books

Heath, C. and Hindmarsh, J. (2002) 'Analysing Interaction: Video, Ethnography and Situated Conduct', in T. May (ed.), Qualitative Research in Action, Thousand Oaks, California: Sage

Hodder, I. (2000) 'The Interpretation of Documents and Material Culture', in N.K.
2 We confirmed off-record that our interpretation of these two incidents was correct.

Denzin and Y.S. Lincoln (eds), Handbook of Qualitative Research, Thousand Oaks, California: Sage

Potter, J. and Wetherall, M. (1987) Discursive and Social Psychology: Beyond Attitude and Behaviour, London, Sage

Rich, M.; Lamola, S.; Gordan, J. and Chalfen, R. (2000) 'Video Intervention/prevention Assessment: A Patient-centered Methodology for Understanding the Adolescent Illness Experience', Journal of Adolescent Health 27: 155-65

Sarbin, T.R. (ed.) (1986) Narrative Psychology: The Storied Nature of Human Conduct, New York: Praeger

Wadsworth, Y. (1998) 'What is Participatory Research?' in Action Research International, Paper 2, www.scu.edu.au/schools/gcm/ar/ari/ p-ywadsworth98.html (accessed 21 March 2007) 